\title{
The Effects of Fluctuating Air Streams on the Output of a Wind Turbine
}

\author{
Bnan Al-Qallab*, Hamzeh Duwairi \\ Mechanical Engineering Department, The University of Jordan, Amman 11942, Jordan
}

Corresponding Author Email: Bnanalgallab@gmail.com

https://doi.org/10.18280/ejee.210105

Received: 5 December 2018

Accepted: 1 February 2019

\section{Keywords:}

boundary layer, electricity production, surface topography, velocity fluctuations, wind energy

\begin{abstract}
The objective of this work is to model the fluctuating air stream potential of producing wind energy and study different operating parameters of wind turbines, by using conservation principles continuity and momentum, with wind turbine equations. A combination of two numerical methods which include Runge-Kuttha technique with shooting technique were utilized using MATLAB to obtain numerical solutions. It is found that the increasing of corrugated surface amplitudes decreases velocities inside boundary layers and reduce power output compared to those obtained by Blasius or traditional Pet theory.
\end{abstract}

\section{INTRODUCTION}

Wind is a form of solar energy, it is formed as a result of the dissimilar heating of the atmosphere by the sun, earth's surface irregularities and rotation of the world. The exploitation of wind energy for power generation functions is becoming step by step more attractive and achieving a substantial share within the electrical power production market globally.

When talking about surface roughness, the more the surface is roughened the greater the boundary layer thickness will be and the turbulence level will increase as well. Furthermore, the effect of the roughened surface density is vital, a higher density increases fluctuating level and boundary layer height. The roughness density is the area of the obstacle divided by the surface area. As the density increases so does the roughness of the system, but a point comes where adding new elements will lighten the roughness of the surface, a group of similar height obstacles is less rough than that with different heights [1].

Surface features that have quite a severe impact on velocity profile is the presence of forestry, urbanized structures and topography features such as sinusoidal hills. As the wind moves into such features, the logarithmic profile will be distorted due to the drag forces exerted by a building for example. As would be expected, the mean horizontal wind speed is reduced when the effect of the roughed surface is considered.

About the amplitude of the flow wave, for high amplitudes; the presence of separated flow regions must be considered. For these type of flow situations, the complete time dependent Navier-Stokes equations need to be solved.

In this manuscript a theoretical model is analyzed and numerically solved by developing a numerical technique to solve governing differential equations. The fluctuations of wind power output as a result of the topography and the presence of obstacles or corrugated surfaces are studied under the effect of fluctuating wind streams.

\subsection{Corrugated surfaces hydrodynamics and surface topology}

Cian examines the possibility of using state of the art measurement and modelling techniques to understand the structure of both forest canopies and the atmosphere above. a full resource assessment for a moderately complex site in the Eastern Scottish Borders region containing 22 wind turbines were performed. A total of 60 sets of results were submitted by 56 organisations located in 17 European countries [2].

Cabezon et al., described the analysis of the elliptical wake model CFD Wake in contradiction of experimental data from wind farm sited in complex terrain Elliptic CFD demonstrating of wakes in complex territory wind farms taking in consider the actuator plate idea is useful. It is presumed that linear superposition of topographic and wind turbine wakes prompts an invalid guess dependent on the consequences of the approval procedure directed in wind cultivate situated in complex landscape [3]

István et al., studied the factors touching wind-energy potential in low settled urban environments. The take a look at interval is that the transition between summer and winter, as a secondary wind most period. Extrapolation to higher levels is feasible by shaping the Hellmann exponent. The outcomes were contrasted to the surface cover of the encompassing space furthermore on the literary alpha values [4].

Sengupta obtained a numerical solution for fully developed turbulent flow over small amplitude sinusoidal wavy surfaces. The cases considered are for both rigid and flexible surfaces. For the rigid surface case, the numerical solution indicated no drag reduction. On the contrary, the total drag of such a surface is more than the drag of an equivalent flat plate. The predictions are in excellent agreement with recent experimental data for rigid wavy surfaces [5].

\subsection{Wind velocity profiles}

Cattin et al. performed "Alpine Wind harvest", CFD wind modeling with WindSim for 7 destinations. Approval of the demonstrating results was executed to estimate wind climatologies and by contrasting vertical wind profiles with profiles estimated by SODAR. WindSim is proper for extrapolation of estimations within short distances and extrapolations from sufficiently high estimates of height to 
hub height. Great estimations at a height of $30 \mathrm{~m}$ as least over the ground [6].

Mohr et al. (2014), enforced a forest canopy within the WRF mesoscale model so as to analyze the aptitude of the mesoscale model for wind resource assessment over wooded areas. It appears that the majority model reflects the forest behavior higher than the forest cover model. The results indicate that wind speeds would like over ten kilometer distance to totally fits the forest surface at a hundred and fifty $\mathrm{m}$ height higher than ground. However, more validation is required [7].

Drew et al. bestowed wind speed profile knowledge obtained from a doppler lidar in central London, UK, throughout an eight-month observation. To calculate the potential wind loading on a tall building in an urban area, a correct illustration of the wind speed profile is needed. For heights below five hundred $\mathrm{m}$, the anticipated wind speed remains among the ninety fifth confidence interval of the measured information. However, once the surface roughness is calculable using land use as a proxy, the model tends to overestimate the wind speed, notably for terribly wind speed periods. These results highlight the importance of an in depth assessment of the character of the surface once estimating the wind speed on top of an urban surface [8].

Antonio Segalini et al. reported the velocity statistics and spectra measured above a wind-tunnel forest model. Several measurement stations downstream of the forest edge have been investigated and it is observed that, while the mean velocity profile adjusts quickly to the new canopy boundary condition, the turbulence lags behind and shows a continuous penetration towards the free stream along the canopy model. A new scaling for the spectra of all three velocity components is proposed based on the velocity variance and integral time scale, a comparison of the proposed scaling laws for two different canopy densities is shown, demonstrating that the vertical velocity variance is the most sensible statistical quantity to the characteristics of the canopy roughness [9].

Okulov et al. carried out LDA experiments to study the development of mean velocity profiles of the very far wake behind a wind turbine model in a water flume. The model of the rotor is placed in a middle of the flume. The initial flume flow is subjected to a very low turbulence level, limiting the influence of external disturbances on the development of the inherent wake instability. The rotor is three-bladed and designed using Glauert's optimum theory at a tip speed ratio $\lambda=5$ with a constant of the lift coefficient along the span, $\mathrm{CL}=0.8$. The wake development has been studied in the range of tip speed ratios from 3 to 9 , and at different cross-sections from 10 to 100 rotor radii downstream from the rotor. By using regression techniques to fit the velocity profiles it was possible to obtain accurate velocity deficits and estimate length scales of the wake attenuation. The data are compared with different analytical models for wind turbine wakes [10].

\subsection{Wind turbulence}

Odemark et al., investigated the impact of shear and turbulence on turbine performance employing a small- scale turbine model in a wind tunnel. This underlines the very fact that not solely the rotor however additionally the tower and also the bearings of a turbine should stand up to redoubled loads once operational near to a canopy. The outcomes point to that the common power coefficient is a smaller amount for the lowest hub height [11].
Ali Al-Abadi et al. conducted Experimental investigations by exposing an efficient wind turbine model to different turbulence levels in a wind tunnel. Nearly isotropic turbulence is generated by using two static squared grids: fine and coarse one. The developments of turbulence scales in the flow direction at various Reynolds numbers and the grid mesh size are measured. Those measurements are conducted with hotwire anemometry in the absence of the wind-turbine. The study shows the higher the turbulence level, the higher the power coefficient. In addition, higher turbulence helps in damping the tip vortices. Thus, reduces the tip losses. Adding winglets to the blade tip will reduce the tip vortex. Further investigations of the near and far wake-surrounding intersection are performed to understand the energy exchange and the free stream entrainment that help in retrieving the velocity [12].

\subsection{Wind energy and wind turbine}

De Juan and Tameemi displayed the look and performance to model an approach for sizing a domestic turbine in an explicit position. This unfold sheet makes use of the key parameters that are modifiable by use of sliders and dropdowns within the model interface and facilitates the sizing of a domestic turbine which may be contrasted against a typical household and yields a simple price analysis [13].

Agravat et al., optimized commercially available windturbines to operate at certain wind velocity, known as rated wind velocity. For other values of wind velocity, it has different output which is lower than the rated output of the wind plant. A theoretical simulation has been done to prove a new concept about swept area of wind turbine blade which results in a significant increase in the power output through the year. Simulation results of power extracted through normal wind blade design and new concept are studied and compared. The findings of the study are presented in graphical and tabular form. Study establishes that there can be a significant gain in the power output with the new concept [14].

Mitiku et al., developed a model to produce optimal energy components for a typical rural community for minimizing the total net present cost of the system through the life time of the project [15].

Omar et al., developed a mathematical model to study the parameters that affect the electrical power generated by the wind turbines. The considered parameters are turbine swept area, air density, wind speed, and power coefficient as a function of pitch angle and blade tip speed. The study shows that the operational parameters has a direct effect on the generated power which will lead the developers and researchers to focus on the highest priority parameter that should be considered for manufacturing and optimizing the new generations of wind turbines [16].

The topography of surface or the presence of obstacles such as: Buildings, trees or hills would absolutely affect the hydraulic characteristics, wind velocity and wind power output through boundary layer. Common modules utilized in wind industry nowadays cannot capture Such characteristics. Modeling around hilly terrain would ask for data concerning the upstream conditions, one among the challenges within numerical flow simulations in complex terrain is to line applicable boundary conditions.

To solve these defects, this paper establishes a new mathematical model based on conservation principles, continuity and momentum, with wind turbine equations in 
order to investigate wind power output, efficiency and the hydraulic characteristics through boundary layer, this includes derivation of governing differential equations, writing them in a dimensionless form and solving the resultant equation numarically using MATLAB.

The remainder of this paper is organized as follows: Section 2 introduces the problem formulation and the modeling concept, Section 3 describes the numerical results obtained and section 4 integrates conclusions and recommendations.

\section{MATH}

Considering steady state wind loads for short periods can incorporate steady state wind model. In addition, the involving of incompressible wind model is usual; this is due to small forces of wind compared to a ramjet or turbojet.

\subsection{GOVERNING equations}

The corrugated surface can be described by the following equation:

$y=\sigma(x)=a \sin \left(\frac{2 \pi x}{\lambda}\right)$

where $a^{*}$ is the amplitude of the wavy surface. It may take values from zero to one and even greater than 1 because it reflects -in physics- the height of hills or buildings relative to distance between them. If $a$ is greater than one; forests of trees near each other are considered, if it is smaller than one; distributed or extended hills are considered, $\lambda$ is the characteristic length associated with the wave and is the surface profile of the tidal waves.

The laminar boundary-layer governing equations are:

The continuity equation:

$\frac{\partial u}{\partial x}+\frac{\partial v}{\partial y}=0$

The x-momentum equation:

$u \frac{\partial u}{\partial x}+v \frac{\partial u}{\partial y}=-\frac{1}{\rho} \frac{\partial P}{\partial x}+v\left(\frac{\partial^{2} u}{\partial x^{2}}+\frac{\partial^{2} u}{\partial y^{2}}\right)$

The y-momentum equation:

$u \frac{\partial v}{\partial x}+v \frac{\partial v}{\partial y}=-\frac{1}{\rho} \frac{\partial P}{\partial y}+v\left(\frac{\partial^{2} v}{\partial x^{2}}+\frac{\partial^{2} v}{\partial y^{2}}\right)$

This is a system of elliptic, nonlinear partial differential equations of the second order. They are accompanied by initial and boundary conditions. Here $\mathrm{u}, v$ are the axial and normal velocity components in the $x$ and $y$ directions respectively, $\mathrm{p}$ is the fluid pressure and $v$ is the Kinematic viscosity which equals $\left(v=\frac{\mu}{\rho}\right)$.

The corresponding boundary conditions for the present problem are:

$u=0, \mathrm{v}=0 \quad$ at $y=0$

$u=u \infty$ at $y \rightarrow \infty$

Here, the following non-dimensional variables are:

$$
y^{*}=y-\sigma(x) \quad x^{*}=\frac{x}{\lambda} \quad a^{*}=\frac{a}{\lambda}
$$

$v^{*}=v-\sigma x u \quad u^{*}=u$

The flow is governed by the following dimensionless form of the governing equations after using the proper nondimensional transformation variables (6) which can be written as:

The x-momentum equation:

$u^{*} \frac{\partial u^{*}}{\partial x^{*}}+v^{*} \frac{\partial u^{*}}{\partial y^{*}}=\frac{1}{\rho} \frac{\partial p}{\partial y^{*}} \sigma x+\left(1+\sigma x^{2}\right) \frac{\partial^{2} u^{*}}{\partial y^{* 2}}$

The y-momentum equation:

$\sigma x\left(u^{*} \frac{\partial u^{*}}{\partial x^{*}}+v^{*} \frac{\partial u^{*}}{\partial y^{*}}\right)=-\frac{1}{\rho} \frac{\partial p}{\partial y^{*}}+v \sigma x\left(1+\sigma x^{2}\right) \frac{\partial^{2} u^{*}}{\partial y^{* 2}}-$ $\sigma x x u^{* 2}$

By Combining equations (7) and (8) and eliminating $\frac{\partial p}{\partial y}$ from them, the resultant equation is expressed as follows:

$u^{*} \frac{\partial u^{*}}{\partial x^{*}}+v^{*} \frac{\partial u^{*}}{\partial y^{*}}=v\left(1+\sigma x^{2}\right) \frac{\partial^{2} u^{*}}{\partial y^{* 2}}-\frac{\sigma x \sigma x x u^{* 2}}{1+\sigma x^{2}}$

where,

$\sigma x=\frac{d \sigma(x)}{d x}, \sigma x x=\frac{d^{2} \sigma(x)}{d x^{2}}$

Then, the following transformations are introduced and the use of well-known relations between velocity components $\mathrm{u}, \mathrm{v}$ and stream function $\psi$ is integrated, in order to reduce the boundary layer equation to an equation with a single dependent variable by changing the partial differential equation (PDE) to ordinary differential equation (ODE), let:

$\eta=\sqrt{\frac{u_{\infty}}{v x}} y, \psi(x, y)=\sqrt{u \infty v x} f(\eta)$

where, $\eta$ is a similarity variable and $\psi$ is the stream function.[17] The transformations given in Equation (10) are introduced into Equation (9), the momentum equation is transformed to the following form:

$\left(1+\sigma x^{2}\right) f^{\prime \prime \prime}+\frac{1}{2} f f^{\prime \prime}-\frac{\sigma x \sigma x x}{1+\sigma x^{2}} x f^{\prime 2}=0$

The corrugated surface function transformation to nondimensional derivatives is represented as follows:

$$
\begin{aligned}
& y=\sigma(x)=a \sin \left(\frac{2 \pi x}{\lambda}\right) \\
& \sigma^{*}(x)=\sigma(x) \\
& \sigma x^{*}=\sigma x \\
& \frac{\sigma x x *}{\lambda}=\sigma x x
\end{aligned}
$$

That results in the following resultant equation:

$f^{\prime \prime \prime}-\frac{\sigma x^{*} \sigma x x^{*}}{\left(1+\sigma x^{* 2}\right)^{2}} x^{*} f^{\prime 2}+\frac{1}{2\left(1+\sigma x^{* 2}\right)} f f^{\prime \prime}=0$

The boundary conditions associated by equation (2.15) take the following form: 
$f(\eta)=0, f^{\prime}(\eta)=0 \quad$ at $\eta=0$

$f^{\prime}(\eta)=1 \quad$ at $\eta=\infty$

The following equations are used to calculate $\eta_{1}, \eta_{2}$ at specific Rex, $y$ and $x$.

$\eta_{1}=\frac{y_{1}}{x} \sqrt{\operatorname{Rex}}$

$\eta_{2}=\frac{y_{2}}{x} \sqrt{\operatorname{Rex}}$

where, $\mathrm{x}^{*}$ is the distance along corrugated surface as dimensionless distance, it describes the shape of corrugated surface as it ends on $\mathrm{x}^{*}$, it also ranges from $(0-1), \mathrm{x}$ is the dimensional distance on earth, $y_{1}$ equals the hub height minus the turbine radius, and $y_{2}$ is the hub height plus the radius.

\subsection{Power calculations}

The actual wind power extracted by the rotor blades can be calculated under the effect of a corrugated surface using the following resultant formula.

The general power equation is represented below [18].

$P(u(0, R))=\frac{1}{2} \rho A u^{3}(0, R) C p$

$P=\int_{A} \frac{1}{2} \rho u^{3} C p d A=\int_{y_{1}}^{y_{2}} \frac{1}{2} \rho u^{3} C P d y$

The potential power is calculated by considering the integration on turbine blades center to outside radius where area is $(2 \pi \mathrm{rdr})$ and the radius changes from 0 to $\mathrm{R}$ Which can be expressed as the area enclosed by $f^{\prime}(\eta)$ curve and limited by the turbine swept area.

$$
u=u \infty f^{\prime}(\eta) \eta=\frac{y}{x} \sqrt{\operatorname{Rex}} \rightarrow d \eta=\frac{d y}{x} \sqrt{\operatorname{Rex}}
$$

$P=\int_{\eta_{1}}^{\eta_{2}} \frac{1}{2} \rho u \infty^{3} \frac{x}{\sqrt{\operatorname{Rex}}} f^{\prime 3}(\eta) d \eta$

$P \frac{\sqrt{\operatorname{Rex}}}{\frac{\rho u \infty^{3} x}{2}}=\int_{\eta_{1}}^{\eta_{2}} f^{\prime 3}(\eta) d \eta$

The non-dimensional wind power is expressed as follows:

$P^{*}=\int_{\eta_{1}}^{\eta_{2}} f^{\prime 3}(\eta) d \eta$

Another power terms must be introduced here "pet power" as the power calculated by substituting freestream velocity outside BL, it is the power of the freestream without involving $\mathrm{BL}$ and the associated friction effects.

Ppet $=0.5 * \rho * U \infty^{3} * C p$

That results in the upcoming non-dimensional term of power:

$P^{*}=\frac{P}{P p e t}$
And "Blasius power" when talking about two-dimensional steady flow of an incompressible constant property fluid over a semi-infinite flat plate. So calculating power ratio according to Blasius will have the following formula:

$P^{*}=\frac{P}{P \text { Blasius }}=\frac{\int_{\eta_{1}}^{\eta_{2}} f^{\prime 3}(\eta) d \eta}{\int_{\eta_{1}}^{\eta_{2}} f^{\prime 3}(\eta) d \eta}$

Tip-Speed-Ratio (TSR) can be calculated based on radius $(\mathrm{R})$, rotational speed or rotor tip speed $(\omega)$ of an elected wind turbine and wind velocity. The following formulas will simplify the equations for calculating TSR.

Wind velocity $(U)=\int_{\eta_{1}}^{\eta_{2}} f^{\prime}(\eta) d \eta$

$T S R=\frac{\omega * R}{U}$

\section{FIGURES}

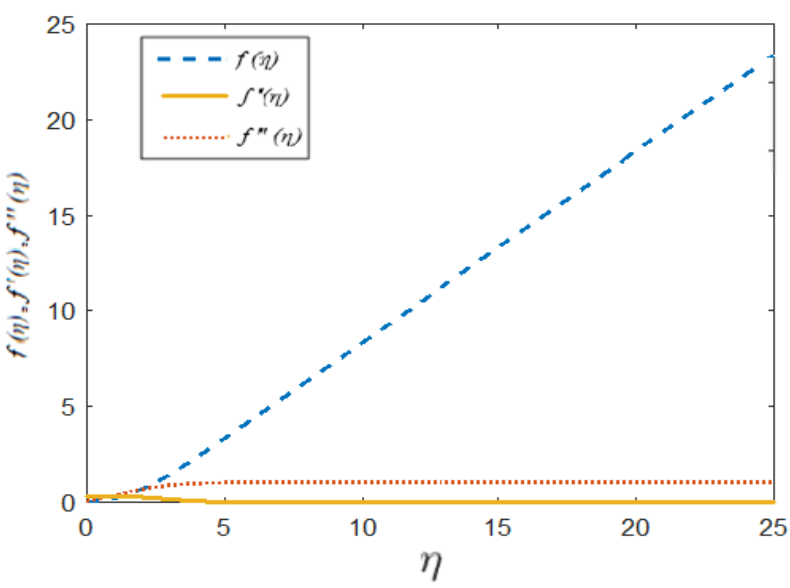

Figure 1. The dimensionless velocity $f^{\prime}(\eta)$, sheer stress $f^{\prime \prime}$ $(\eta)$ and stream function $f(\eta)$ profiles when $\mathrm{x}^{*}=0.5$ and $a^{*}=0$

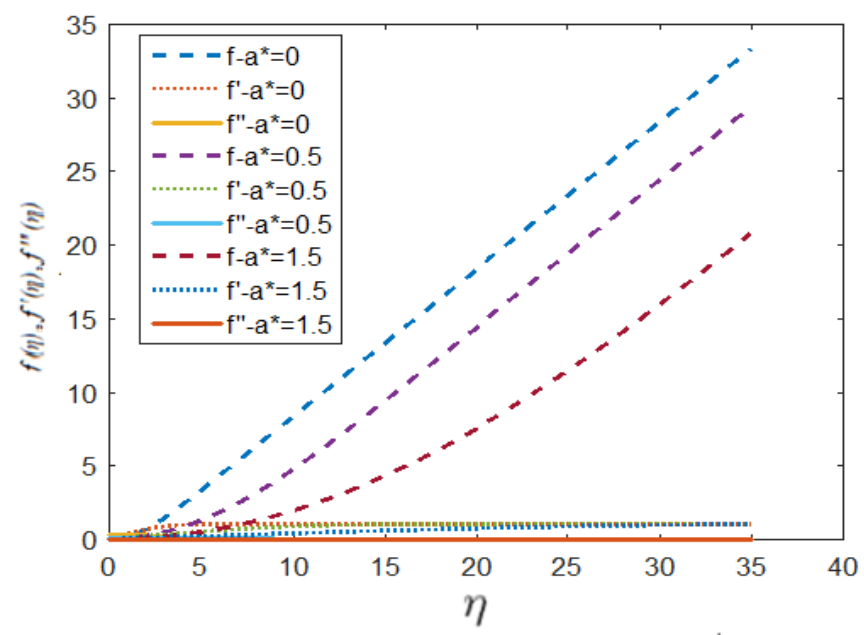

Figure 2. The dimensionless velocity $f^{\prime}(\eta)$, sheer stress $f^{\prime \prime}$ $(\eta)$ and stream function $f(\eta)$ profiles for different values of $a^{*}=(0,0.5,1.5)$ and $\mathrm{x}^{*}=0.5$ 


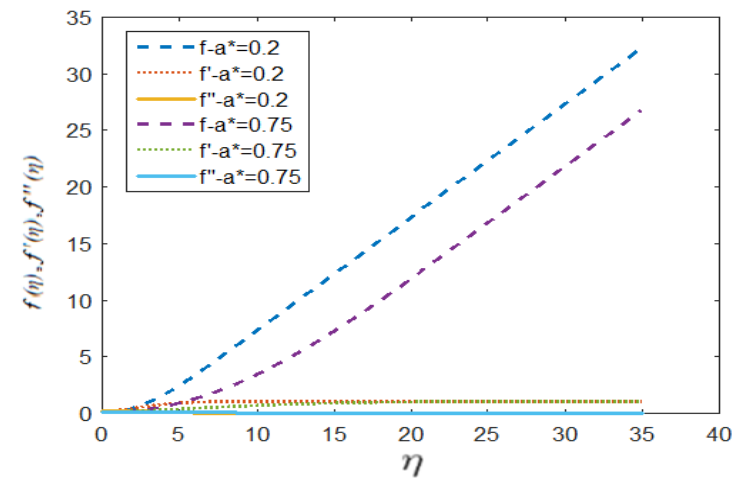

Figure 3. The dimensionless velocity $f^{\prime}(\eta)$, sheer stress $f^{\prime \prime}$ $(\eta)$ and stream function $f(\eta)$ profiles for different values of $a^{*}=(0.2,0.75)$ and $\mathrm{x}^{*}=0.5$

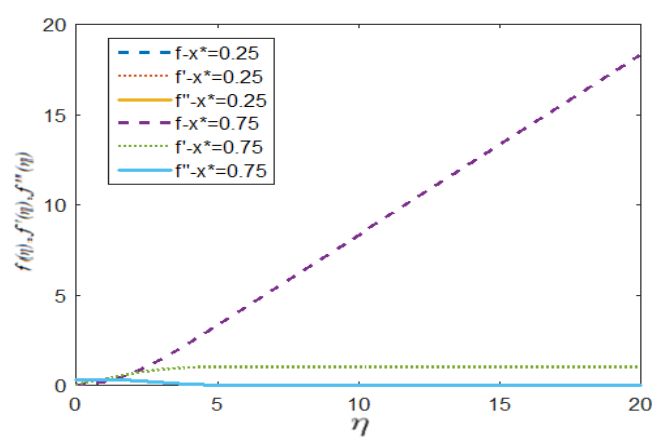

Figure 4. The dimensionless velocity $f^{\prime}(\eta)$, sheer stress $f^{\prime \prime}$ $(\eta)$ and stream function $f(\eta)$ profiles with respect to $(\eta)$ when $\mathrm{x}^{*}=(0.25,0.75)$ and $a^{*}=0.1$

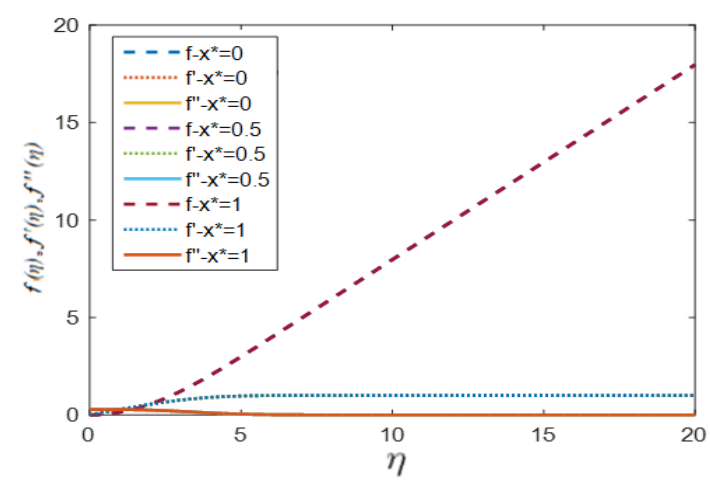

Figure 5. The dimensionless velocity $f^{\prime}(\eta)$, sheer stress $f^{\prime \prime}$ $(\eta)$ and stream function $f(\eta)$ profiles with respect to $(\eta)$ when

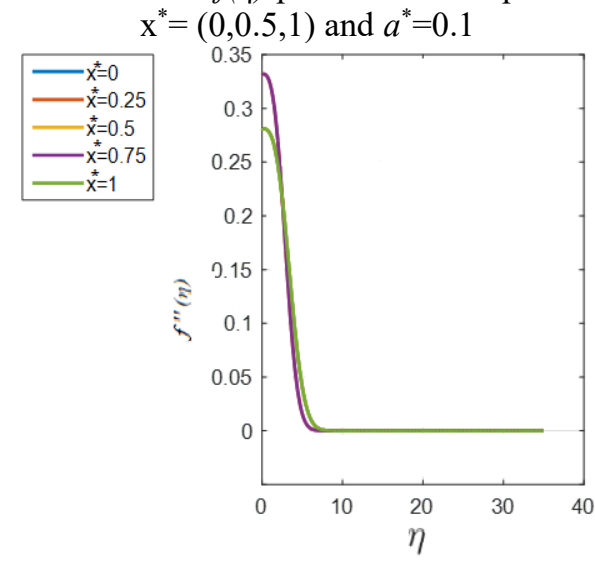

Figure 6. Shear stress $f^{\prime \prime}(\eta)$ for different values of $x^{*}$ and $a^{*}=0.1$
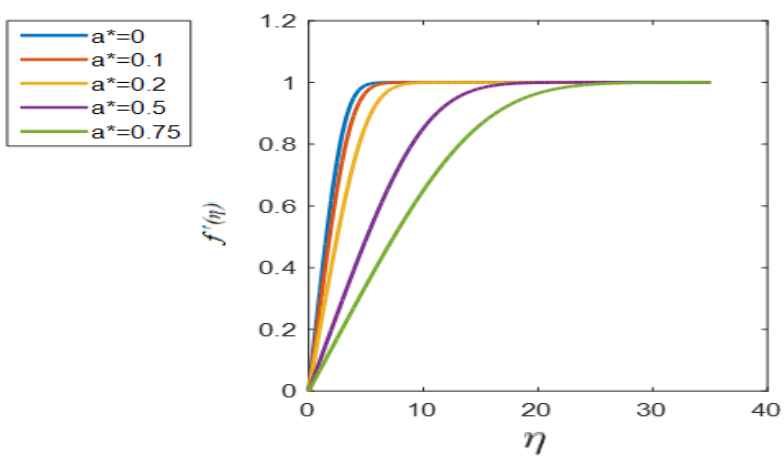

Figure 7. Velocity profile $f^{\prime}(\eta)$ for different values of $a^{*}$ and $\mathrm{x}^{*}=0,0.5,1$
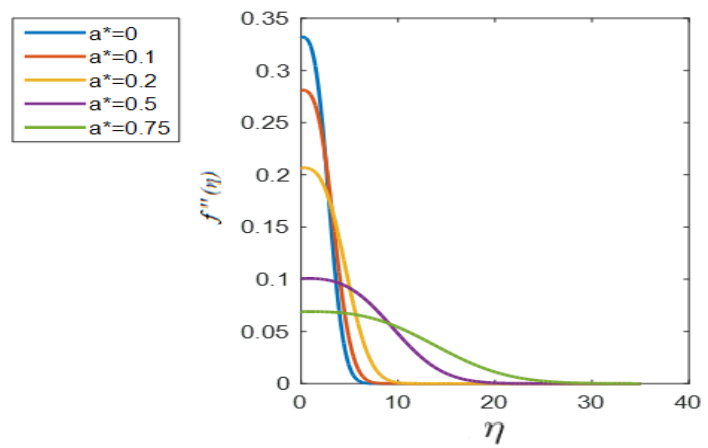

Figure 8. Shear stress $f^{\prime \prime}(\eta)$ for different values of $a^{*}$ and $\mathrm{x}^{*}=0,0.5,1$

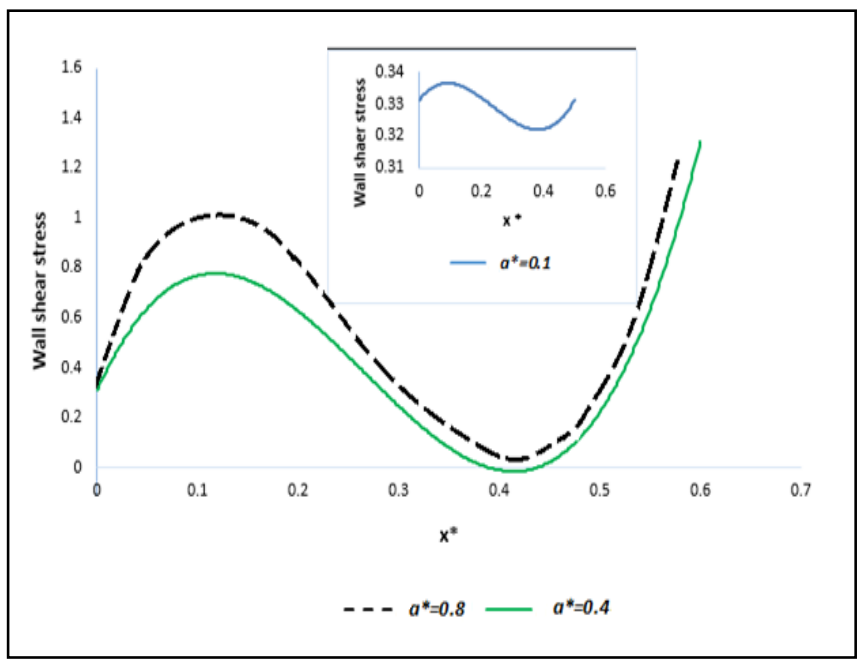

Figure 9. Wall shear stress for different values of $\mathrm{a}^{*}$ and $\mathrm{x}^{*}$

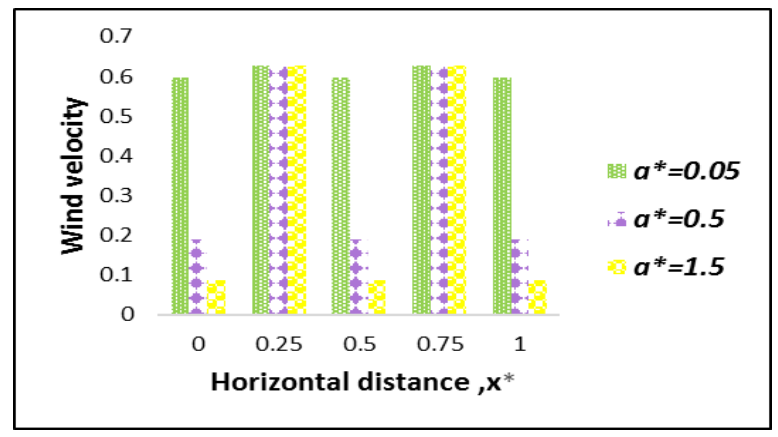

Figure 10. Wind velocity versus $\mathrm{x}^{*}$ for different values of $a^{*}$ where Hhub $=100, \mathrm{R}=10, u_{\infty}=5$ and $\mathrm{Rex}=4 * 10^{5}$ 


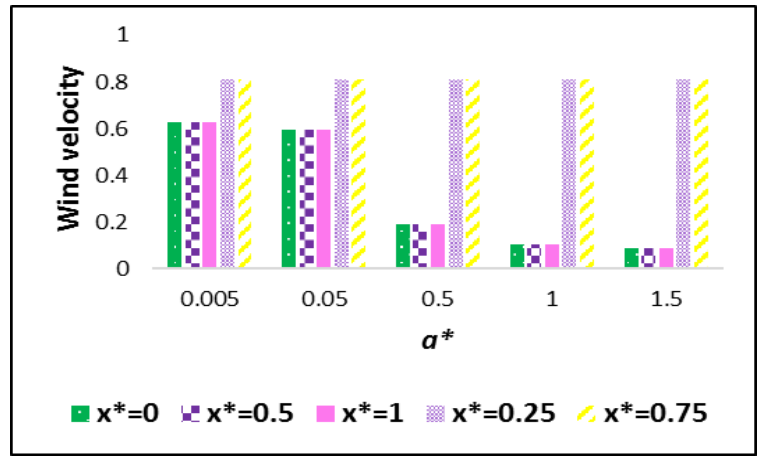

Figure 11. Wind velocity versus $a^{*}$ for different values of $\mathrm{x}^{*}$ where Hhub $=100, \mathrm{R}=10, u_{\infty}=5$

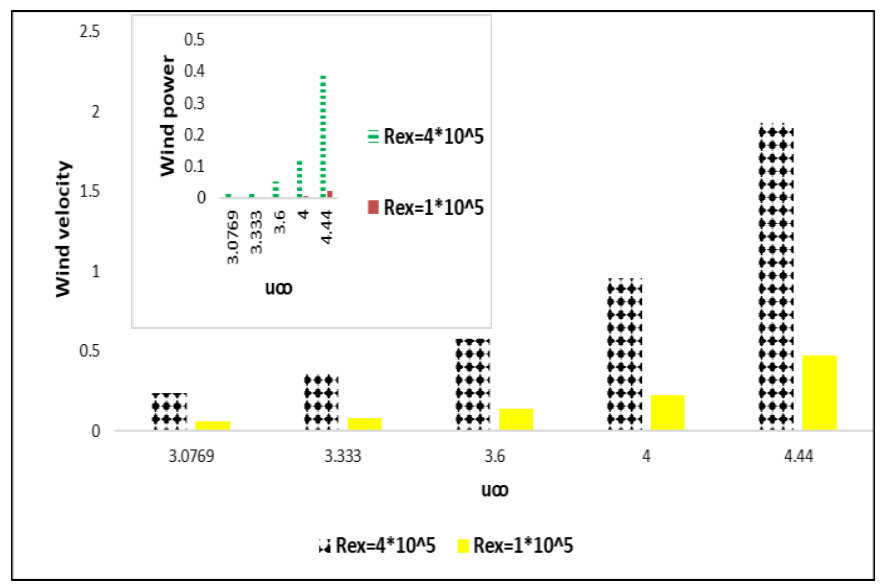

Figure 12. Wind velocity for different values of Rex and $u_{\infty}$, where Hhub $=100, \mathrm{R}=10, \mathrm{x}^{*}=0.5$ and $a^{*}=0.5$

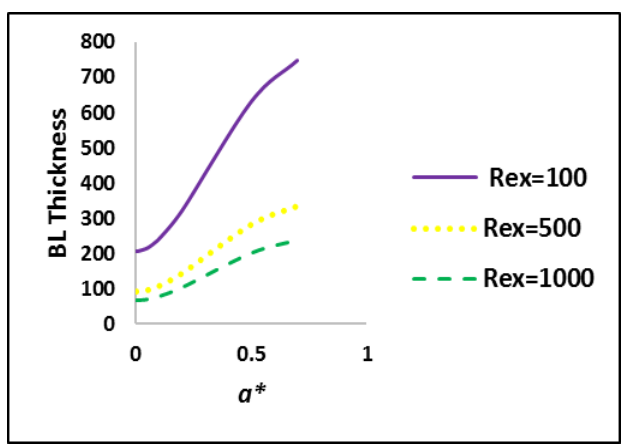

Figure 13. A representation of BL thickness based on the value of (y) at which $f^{\prime}(\eta)=1$

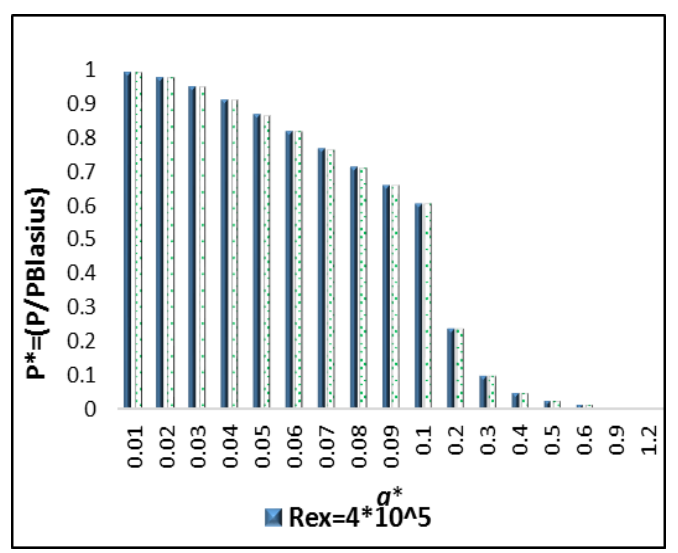

Figure 14. Wind power ratio versus wave amplitude atdifferent Reynolds numbers

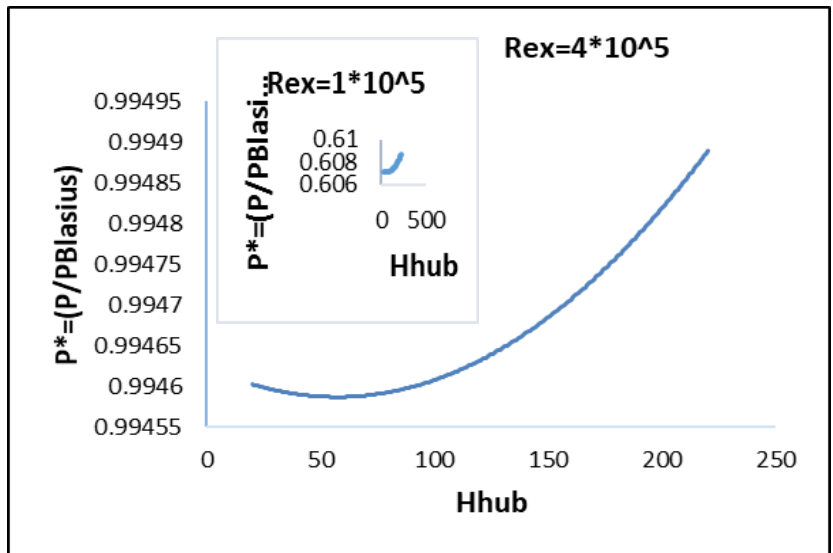

Figure 15. Wind power ratio against different turbine heights and $\operatorname{Rex}$ at $a^{*}=0.1$

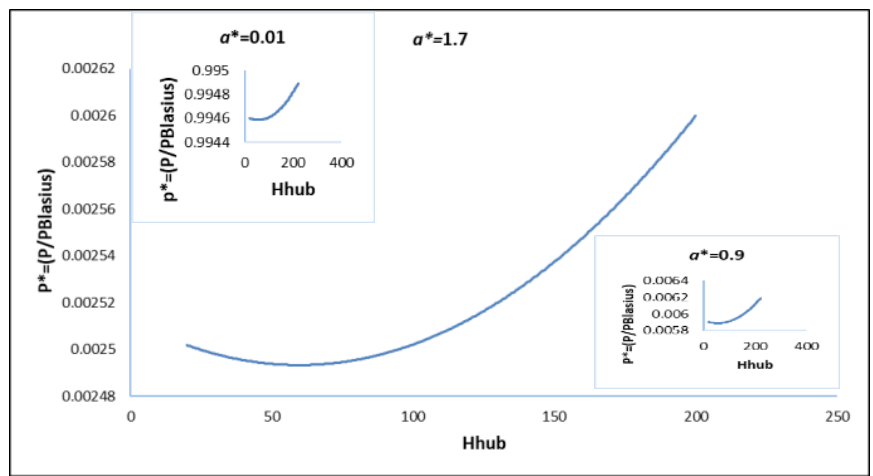

Figure 16. Power ratio versus height for the different amplitudes $\left(a^{*}=1.7,0.9\right.$, and 0.01$)$ with $\operatorname{Rex}=4 * 10^{5}$

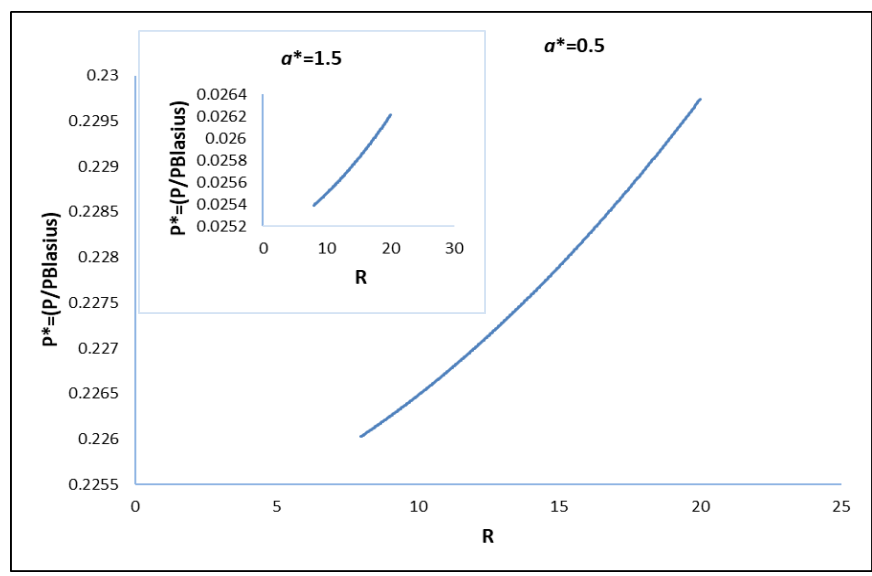

Figure 17. Power ratio versus radius of wind turbineblades for the following amplitueds $\left(a^{*}=0.5,1.5\right)$

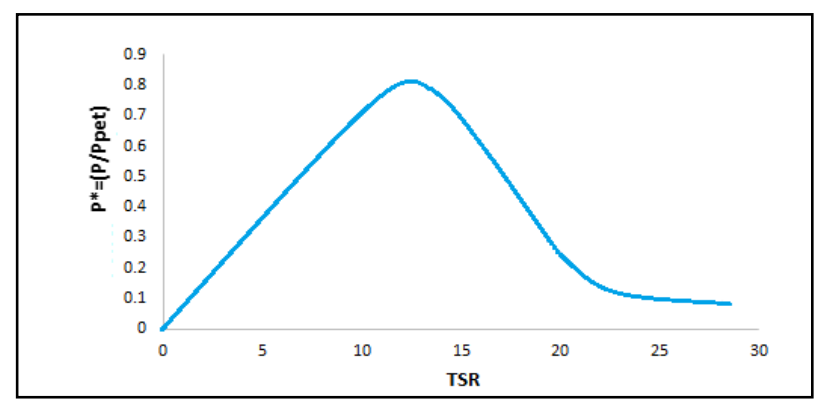

Figure 18. Power ratio versus Tip-Speed-ratio at different amplitudes 


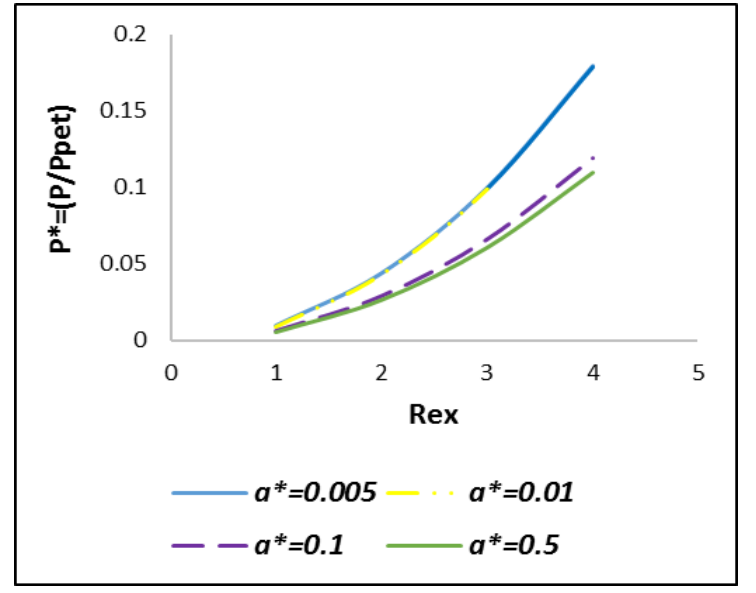

Figure 19. Power ratio (P/Ppet) versus Reynolds number for different wave amplitudes where $x^{*}=(0,0.5,1)$, $\mathrm{R}=10, u_{\infty}=1$ and Hhub $=100$

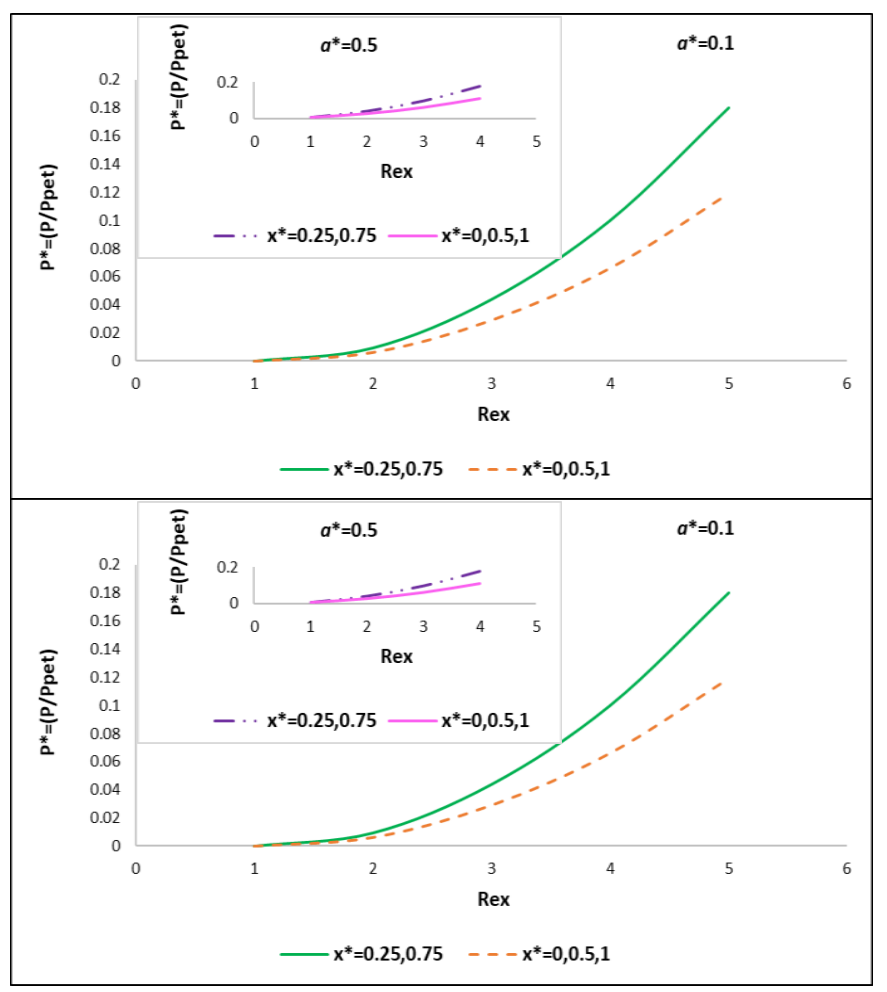

Figure 20. Power ratio (P/Ppet) versus Reynolds number for different $\mathrm{x}^{*}$ and $a^{*}$ where $\mathrm{R}=10, u_{\infty}=1$ and Hhub $=100$

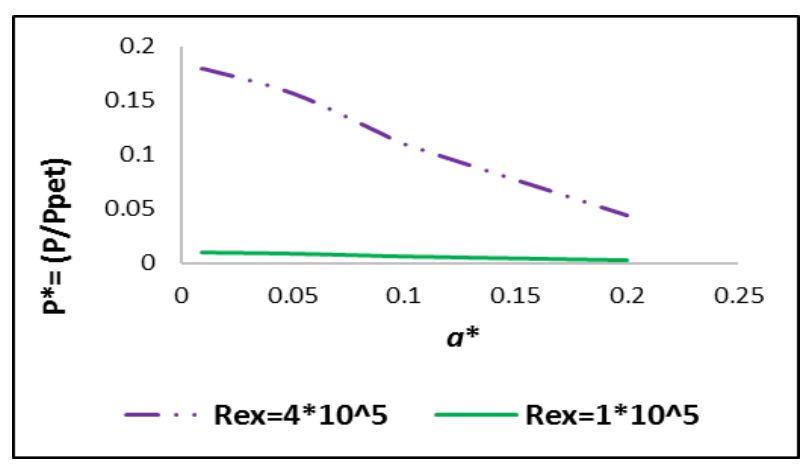

Figure 21. Wind power ratio (P/P pet) against wave amplitude for different Rex

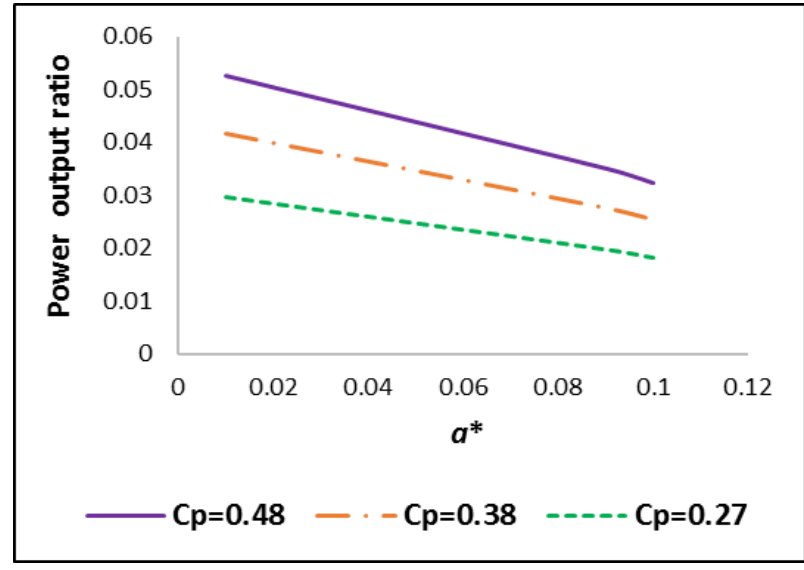

Figure 22. Power output ( $\mathrm{P} / \mathrm{P}$ pet) versus amplitude for different power coefficients

\section{CONCLUSIONS}

Flow over a corrugated surface can affect the hydraulic characteristic of the flow through BL, it is found that the velocity decreases as amplitude values increase, since the velocity is affected slightly when $a^{*}$ is quite small by the roughness of the surface, and almost nothing is hindering wind speed. So, wind speed is smallest when amplitude or roughness of the surface is the most, this is due to higher shear stresses between fluid layers that comes from higher stresses at corrugated surface,

The larger the amplitude is the lesser the velocity will be; the grater the values of shear stress, stream function and wall shear stress $(\tau)$ will become. As $\tau$ reflects the tangential force extended by the flowing fluid resulted by the friction effects on the surface and between fluid layers.

As moving away from the ground, surface effect diminishes rapidly and vanishes completely outside the $\mathrm{BL}$, where the flow velocity returns to the freestream velocity and becomes $f$ $'(\eta)=1$. It is clear that the larger the amplitude is; the grater the BL thickness will be.

The wind power expressed based on Blasius power and Pet power, decreases when considering a corrugated surface compared to that flat one or that stream flow which propagate far away of the surface outside BL. As amplitude values getting larger, the amount of harvested power is lesser, wind power increases as the height of wind turbine increases, and decreases as the radius of wind turbine decreases.

It is found that as amplitude increases the wind velocity decreases, as a result, the wind power decreases as well as TipSpeed-Ratio. Wind power output is grater when TSR is not so large nor so small.

It is clear that higher Rex value means high inertia forces compared to viscous forces, that in turn means that the wind velocity increases when Rex value is larger as well as wind power. It also refers to a small boundary layer thickness, which limits the viscous effects on fluid layer in a small region near the corrugated surface. It is also obvious that the more the value of $u \infty$, the larger the values of wind velocity, where $u \infty$ is calculated based on the value of Rex, $x$ and $v$.

Since the power coefficient of a turbine is a measure of however efficiently the turbine converts the energy within the wind into electricity. The less efficient a turbine is the less of the kinetic energy is converted into electricity. 
The following are suggestions for further investigations based on the previous work:

1) Finding the effect upon wind turbines, wind farms or wind energy generation considering turbulent conditions when $\operatorname{Rex}>5 * 10^{5}$.

2) Studying the effect of fluctuating wind steams on the structure of wind turbine and its base.

3) Integration of corrugated surface function through calculations can be introduced by taking different functions instead of sine functions to describe shape of obstacles such as cosine functions or any combination of both.

\section{REFERENCES}

[1] Hébrard E, Listowski C, Coll P, Marticorena B, Bergametti G, Määttänen A, Montmessin F, Forget F. (2012). An aerodynamic roughness length map derived from extended Martian rock abundance data. Journal of Geophysical Research Atmospheres 117: E04008. https://doi.org/10.1029/2011JE003942

[2] Desmond CJ. (2014). The consideration of forestry effects in wind energy resource assessment. https://doi.org/10.13140/RG.2.2.32022.04166.

[3] Cabezon D, Hansen KS, Barthelmie RJ. (2009). Analysis and validation of CFD wind farm models in complex terrain Wakes induced by topography and wind turbines. Proc. EWEC

[4] István L, Csákberényi-Nagy G, Túri Z, Kapocska L, Tóth T, József Barnabás T. (2014). Analysis of factors affecting wind-energy potential in low built-up urban environments. Conference: Air and Water Components of the EnvironmentAt: Cluj-Napoca, Romania https://doi.org/10.13140/2.1.4231.5200

[5] Sengupta TK. (1984). Turbulent boundary layer over rigid and moving wavy surfaces. Project: Drag Reduction. https://doi.org/10.13140/RG.2.2.35849.75366

[6] Cattin R, Schaffner B, Kunz S. (2006). Validation of CFD wind resource modeling in highly complex terrain. Meteotest, Fabrikstrasse 14, 3012 Bern, Switzerland, 110.

[7] Mohr M, Jayawardena W, Arnqvist J, Bergström H. (2014). Wind energy estimation over forest canopies using WRF model. Project: Forest wind - Wind Power in Forests II.

[8] Drew DR, Barlow JF, Lane SE. (2013). Observations of wind speed profiles over Greater London, UK, using a Doppler lidar. Journal of Wind Engineering and Industrial https://doi.org/10.1016/j.jweia.2013.07.019 Aerodynamics.

[9] Segalini A, Fransson JHM, Alfredsson PH. (2013). Scaling laws in canopy flows: A wind-tunnel analysis. Boundary-Layer Meteorology https://doi.org/10.1007/s10546-013-9813-2

[10] Okulov VL, Naumov I, Mikkelsen R, Sørensen JN. (2015). Wake effect on a uniform flow behind windturbine model. Journal of Physics, Conference Series $625(1)$

https://doi.org/10.1088/1742
$6596 / 625 / 1 / 012011$

[11] Odemark Y, Segalini A. (2014). The effects of a model forest canopy on the outputs of a wind turbine model. Journal of Physics Conference Series 555(1): 012079. https://doi.org/10.1088/1742-6596/555/1/012079

[12] Al-Abadi A, Youjin K., Ertunç. Ö, Delgado A. (2016). Turbulence impact on wind turbines: experimental investigations on a wind turbine model. Journal of Physics Conference Series 753(3). https://doi.org/10.1088/1742-6596/753/3/032046

[13] Juan A, Tameemi S. (2013). Wind energy analysis wind energy modelling. Conference: Energy Systems Modelling. https://doi.org/10.13140/2.1.3075.1047

[14] Agravat S, Manyam NVS, Mankar S, Tirumalachetty H. (2015). Theoretical study of wind turbine model with a new concept on swept area. Energy and Power Engineering 7(04): 127-134. https://doi.org/10.4236/epe.2015.74012

[15] Mitiku T, Manshahia MS. (2018). Project: Energy Harvesting: Modelling and Optimization of Renewable Energy Systems Using Computational Intelligence.

[16] Badran O, Abdulhadi E, Mamlook R. (1992). Projects: Renewable Energy Research Advanced Intelligent Systems.

[17] Incropera DW, Bergman and Lavine (2007). Fundamentals of Heat and Mass Transfer. (6st ed.), United States of America.

[18] Patel MR. (1999). Wind and solar power systemsdesign, analysis, and operation. Wind Engineering 30(3): 265266. https://doi.org/10.1260/030952406778606197

\section{NOMENCLATURE}

$\mathrm{A}$
$a^{*}$

Swept rotor area in square meter

$a^{*} \quad$ Amplitude-to-length ratio of the wavy surface (wave amplitude)

$\mathrm{Cp} \quad$ Power Coefficient of wind turbine

Hhub Hub height of the wind turbine

$P \quad$ Wind power in watt

$\mathrm{P} \quad$ Pressure anywhere in the field

$\mathrm{R}$ Radius of wind turbine blade

$\mathrm{U}, \mathrm{V}$ Dimensionless velocity components along the $(\mathrm{x}, \mathrm{y})$ axes

$\mathrm{X}, \mathrm{Y}$ Cartesian coordinate component in the direction along and normal to the tangent of the surface

$\Omega \quad$ Rotor speed

$\mathrm{m}^{2}$

Dimensionless

Dimensionless

$\mathrm{M}$

W

$\mathrm{N} / \mathrm{m}^{2}$

$\mathrm{M}$

$\beta\left({ }^{\circ}\right) \quad$ Pitch angle

$\Lambda$ Characteristic length associated with the wavy surface

$v \quad$ Kinematic viscosity

Dimensionless

Differentiation with respect to $\eta$

$\mathrm{f}^{\prime} \quad$ First order component of $\mathrm{f}$

$\mathrm{F} \quad$ Zeroth order component of $\mathrm{f}$

* Dimensionless quantities

\section{M}

$\mathrm{Rad} / \mathrm{s}$

Degrees $\left({ }^{\circ}\right)$

$\mathrm{M}$

$\mathrm{m}^{2} / \mathrm{s}$ 